\title{
Bioética de intervenção e justiça: olhares desde o sul
}

\section{Intervention bioethics and justice: views from the south}

\author{
Cristiane Alarcáo Fulgêncio \\ Universidade de Brasília, Brasília, Brasil. \\ cristianefulgencio@gmail.com \\ Wanderson Flor do Nascimento \\ Universidade de Brasília, Brasília, Brasil. \\ wandersonn@gmail.com
}

Resumo: Este artigo se divide em três partes: A primeira apresenta como a Bioética de Intervenção abarca a questão da justiça social em seu escopo teórico. A segunda parte mostra duas concepçóes sobre justiça social a partir de duas comunidades: uma comunidade latino-americana e outra africana. A terceira parte propóe um diálogo entre a Bioética de Intervenção e as abordagens que tais comunidades trazem sobre a justiça social no sentido de colaborar e enriquecer as suas bases teóricas.

Palavras chave: Bioética de intervenção. Justiça social. Vulnerabilidade. América Latina. África.

\begin{abstract}
This article is divided into three parts. The first part presents how intervention bioethics embraces the issue of social justice within its theoretical scope. The second part shows two conceptualizations of social justice, from two communities: one Latin American and the other African. The third part proposes a dialogue between intervention bioethics and the approaches that these communities bring in relation to social justice, so as to contribute to and enrich its theoretical basis.
\end{abstract}

Keywords: Intervention bioethics. Social justice. Vulnerability. Latin America. Africa.

No contexto da elaboração das chamadas bioéticas sociais, que se vinculam a outros aspectos que náo os apenas biomédicos da avaliaçáo de tensóes relativas às moralidades no que concerne a fenômenos relacionados com a vida, a Bioética de Intervenção (BI) se estrutura como uma proposta de repolitização de conflitos morais, que tem como orientação posicionar-se do lado dos mais vulneráveis em face às múltiplas esferas de poder no âmbito social (1). Contrapondo-se a uma bioética limitada a alguns princípios (beneficência, não-maleficência, autonomia e justiça) oriundos da bioética principialista, cujos paradigmas universais e hegemonizantes, a BI se inscreve a partir de uma posição laica e combativa aos problemas sociais. Ela ultrapassa o âmbito da 
clínica médica e alcança o mundo da vida em geral. Nesse sentido, ela perpassa os problemas sociais que são subjacentes, principalmente, àquelas sociedades advindas da parte sul do planeta.

O local de discussão da BI é o sul, ou seja, o conjunto de regiôes geopolíticas vulneradas pela economia de mercado $(2,3)$. É desde o sul que a BI situa sua reflexão sobre a vulnerabilidade social e o papel da intervenção para a resoluçáo de conflitos bioéticos (1). A importância de delimitar o local se estabelece na medida em que será a partir desse lugar que a BI irá se posicionar como uma bioética de cunho social.

A questão da justiça social, nos países periféricos, será de fundamental importância para as bioéticas sociais. Essa abordagem se estabelece a partir dos sujeitos que são atravessados por realidades econômicas, sociais e culturais, as quais afetarão o seu acesso aos serviços de forma geral e, por conseguinte, a sua qualidade de vida.

A discussão bioética estabelecida nesse cenário evoca uma reflexão sobre o contexto da justiça. Que noçáo de justiça está afirmada na BI? Dada sua proposta de pensar desde o sul, que contribuiçôes as reflexóes latino-americanas e africanas poderiam fornecer ao escopo teórico da BI, uma vez que estas são eminentemente desde o sul? Tentar articular algumas das respostas para estas questôes é o objetivo deste artigo. Por reconhecermos a importância política da BI, no cenário hegemônico de corte liberal e asséptico na avaliaçáo de conflitos morais por parte da perspectiva hegemônica em bioética, nos propomos a dialogar com a BI com o propósito de buscar colaboraçóes para o fortalecimento de suas bases teóricas sobre o conceito de justiça social e os seus usos.

\section{A justiça no contexto da Bioética de Intervençáo}

Embora não haja uma teorização sistemática nas bases conceituais da BI sobre a noção de justiça social, há diversos elementos cuja articulação teórica nos permitem entrever a maneira como a BI compreende este conceito. O texto fundante da BI, intitulado Bioética, poder e injustiça: por uma ética de intervenção, foi apresentado no VI Congresso Mundial de Bioética, que teve como tema as relaçóes entre bioética, poder e injustiça e foi realizado em Brasília em 2002. O título do texto, assim como o tema do congresso, já evoca um tipo específico de relaçáo com o tema da justiça social: uma abordagem dialética com relaçáo a seu aparecimento concreto na forma da injustiça.

Este modo de aparição marca a posição ética e política da BI com relação ao tema: o radical e inegociável enfrentamento da injustiça causada pelos mais diversos modos de atuação dos poderes globais no âmbito da economia de mercado, que privilegia o capital e o individual em detrimento do coletivo. A busca por justiça social, então, está completamente vinculada ao combate às iniquidades sociais que impactam o mundo da vida e da saúde (2). Inserindose no contexto histórico da vasta discussão sobre o conceito de justiça, a BI se 
vincula com a discussão sobre a justiça social e a justiça sanitária $(1,4)$.

Influenciada pelas perspectivas de Amartya Sen (5), a BI pensará a justiça social como o combate à iniquidade na busca de uma prática interventiva socialmente comprometida (6) com os segmentos sociais mais fragilizados pelas forças políticas, econômicas e morais que partem das regióes centrais do mundo.

Esta abordagem difere das hegemônicas perspectivas sobre a justiça e, sobretudo, das apropriaçóes da bioética principialista que assume, desde um corte liberal, a primazia da autonomia sobre a justiça, ao operar com determinados princípios, que, embora importantes, são insuficientes, para avaliar os conflitos morais sobre a vida e a saúde. As leituras tradicionais tendem a afirmar a superioridade dos direitos e liberdades individuais sobre os coletivos e a utilizar a perspectiva utilitarista em conformidade com a lógica do mercado (7). A BI tem como um de seus fundamentos teóricos a presença do utilitarismo solidário, orientado para a equidade $(1,8)$. O comprometimento com uma noção crítica de solidariedade e a orientação para a equidade marcam a diferença da abordagem do utilitarismo pela BI. A equidade tem como objetivo atingir a igualdade, que ao redistribuir os bens escassos, busca superar as desigualdades e garantir a justiça (2-9).

Mais uma vez o traço dialético aparece na definição de justiça, que se ancora na necessidade de enfrentar a desigualdade e a iniquidade. Uma vez que a desigualdade e a iniquidade são fenômenos sociais, ao colocar-se em uma proposta radical de intervençáo para a modificação desses fenômenos, a BI se converte em uma potente ferramenta para a busca da justiça social, que atue no auxílio da construçáo de sociedades democráticas comprometidas com as práticas e os valores de cidadania e com os direitos humanos $(9,10)$. A BI, em sua abordagem da justiça social, articulará três importantes categorias para a compreensão das atividades humanas ligadas com a ética e a política: a libertação, noção apropriada da produção de Paulo Freire; o empoderamento, conceito trazido das reflexóes de Amartya Sen e; a emancipação, ideia motriz tanto do Iluminismo quanto de todo o pensamento crítico latino-americano. A articulação dessas três categorias amplia o espectro de análise da BI e possibilita uma série de proposiçóes interventivas que almejem a inclusão social (10).

A BI, como uma das potentes vertentes da bioética latino-americana, ao assumir a tarefa de re-politizar as questóes morais ligadas com a vida e a saúde, através da afirmação da inclusão social, da responsabilidade e da justiça social, tornou-se uma das protagonistas da conquista da politização da agenda bioética mundial, que culminou na presença central de elementos sociais na Declaraçáo Universal de Bioética e Direitos Humanos da Unesco, que se consolida como uma importante proposta para a construçáo de um mundo mais justo $(11,12)$.

\section{Alguns olhares desde o sul sobre a justiça}

Buscar vozes desde o sul, perspectivas teóricas que se originem de 
regiôes nas quais a vulnerabilidade social não é apenas um objeto de investigação acadêmico, mas o modo regular da vida da maior parte da população, pode trazer elementos importantes para a proposta epistemológica e política da BI, na medida em que a aliança com os mais vulneráveis se dê também no plano das escolhas teóricas.

Este contexto de colaboraçáo se enfrenta com o fato duro de que as ideias hegemônicas sobre justiça emergem em um campo social dividido, no qual se cria um conjunto de sujeitos desprovidos de direitos plenos, pela força da colonialidade. Isso implica que existem sujeitos dotados de direitos, para quem a noção de justiça é válida como um mecanismo protetivo, e outros, que não pertencem a essa classe de indivíduos (13). Tentar operar com perspectivas teóricas atentas e enraizadas nessa divisáo e que se posicionem ao lado dos sujeitos historicamente destituídos de justiça, pode ser uma interessante contribuição para a BI.

Nessa busca de colaboração, traremos duas perspectivas do sul sobre a justiça. Uma advinda da América Latina, de suas populaçôes originárias e tradicionais andinas, e outra advinda do velho continente negro, das originárias populaçôes de origem banta; vozes subalternizadas, silenciadas e vulneráveis, que contam, porém, com um vasto e potente conjunto de ideias que, se analisadas com atenção, podem oferecer ferramentas interessantes para pensar o mundo dos valores morais e políticos.

Para a perspectiva andina das comunidades aymaras da Bolívia, a justiça se estrutura como o núcleo de significação que organiza as relaçóes sociais e a interação na sociedade, sendo assim um elemento articulador entre a ética e a política. Está vinculada com a distribuição dos bens comuns, entendidos como um produto das práticas culturais e políticas das sociedades na interação com a natureza (14).

A concepçáo de mundo das comunidades aymaras pressupóe uma interligação entre as comunidades humanas, a natureza e a espiritualidade, para a qual o conjunto de valores humanos deve passar pela compreensão e avaliaçáo dos impactos da açáo para a totalidade do mundo assim interligada, na busca da preservação da vida do todo e na ponderada distribuiçáo dos recursos materiais e culturais por todas as pessoas das atuais comunidades - sem se esquecer da comunidade que virá - a partir das experiências e do modo como se resolveram os conflitos em nossas comunidades presentes e nas configuraçóes passadas da comunidade (14). Este fato conclama a aprender os marcos valorativos das experiências históricas que nos constituíram.

É nesse cenário que a noção de buen vivir emerge como o princípio que estrutura a produção material da vida, a regulação das relaçôes sociais, a partir de uma percepção moral e política que atua ao mesmo tempo como critério de redistribuiçáo da riqueza socialmente produzida e a reprodução do sentido de pertença das pessoas à comunidade (14).

Nas múltiplas e complexas relações estabelecidas nas comunidades 
tradicionais aymaras, temos como princípio básico das relaçôes materiais entre os membros da comunidade a ideia de reciprocidade, que é um dos fundamentos principais da noçáo de justiça (que, para estas percepçóes de mundo, é sempre social). Esta reciprocidade, para além de apontar para uma visão essencialista de uma "boa natureza" dos membros da comunidade aymara, indica um conjunto de relaçóes sociais que possibilitem a construçáo de um horizonte de significação das relaçóes entre o indivíduo e sua coletividade e natureza. Como também a construção de uma noção de bem comum e delimitações restritivas que ofereça normas para o que é permitido ou proibido nas comunidades (14).

A partir dessa centralidade do eixo comunitário, vemos também que é a própria comunidade a responsável pela observação e avaliação da conduta de seus membros, responsabilizando-se pela efetivação da justiça. O objetivo fundamental da justiça na comunidade é reconduzir as condutas ao socialmente aceitável, com um viés nitidamente restaurador de administração coletiva (14).

A noção de reciprocidade sustentada como base da noção aymara de justiça articula-se não com a ideia de igualdade, fundamental para a noção de justiça ocidental, mas com a perspectiva da prestação de serviços à comunidade. Não é um estatuto ontológico que determina o modo como as pessoas devem ser tratadas, mas sua interação com a comunidade. Este marco configura a solidariedade e responsabilidade coletiva como eixo fundamental da noçáo de justiça para essas comunidades. Tal fato, antes de impedir a existência de conflitos, nos oferece uma maneira coletiva de abordá-los, tendo a coletividade como marco fundamental a partir do qual se avalia, julga e decide sobre os conflitos no mundo social. Há uma dimensão corretiva/restaurativa na percepção de justiça aqui afirmada, que sempre toma a solidariedade e a reciprocidade como balizadores, tendo o imperativo da preservação da vida do todo, da comunidade, como estruturante (14).

$\mathrm{Na}$ proposta de afirmação dessa noção de justiça, não devemos esquecer que essas comunidades vivem em contextos interculturais, ou seja, vivem seus valores e práticas tradicionais e interagem com o estado-naçáo boliviano. As perspectivas de articulação entre os dois olhares constitui, em si, um desafio, tanto para o olhar do ocidente quanto para os olhares tradicionais.

O contexto da justiça aqui afirmado se relaciona com uma radical crítica dos modelos econômicos globalizados, na medida em que ele é determinante de todas as outras relaçóes sociais que envolvam as comunidades $(15,16)$. A justiça praticada pelos aymaras, como pelo restante das comunidades indígenas andinas, historicamente foi relacionada com múltiplas relaçóes sociais e econômicas completamente diferentes da lógica individualista, que sustenta a primazia da propriedade individual, a acumulação ilimitada e a mercantilização da vida que o ocidente liberal afirma.

E, mesmo nas diversas relaçóes que estabeleceram com o ocidente colonial, manteve, ao mesmo tempo em que se modificava através das dinâmicas históricas, os fundamentos mais importantes da justiça solidária, recíproca, 
restauradora, afirmadora da vida humana e não humana, que atravessou a dinâmica da colonização. Sem ingenuidades, as comunidades indígenas se relacionaram com o ocidente colonizador, com seu capitalismo voraz, interagindo com o que fosse necessário sem abrir mão de suas bases ancestrais, historicamente afirmadas (16).

A noção relacional de justiça afirmada entre os indígenas andinos, fundada na reciprocidade, difere radicalmente da noçáo ocidental - ao propor um tratamento indiscriminado das pessoas, de acordo com seu valor idêntico e sua dignidade intrínseca e irrestrita. No contexto andino, em função da reciprocidade e do fato de uma inter-relação dos seres humanos com o restante do universo, cada ato é julgado em função do lugar peculiar que cada sujeito ocupa na ordem da comunidade, o que faz com que as pessoas sejam julgadas de maneiras diferenciadas, mesmo quando a ação é supostamente idêntica. Deste modo, o parâmetro fundamental para a avaliaçáo ética - da qual a justiça é uma categoria fundamental - é a ação em função do equilíbrio social, nos níveis familiar e comunitário, que pode ser lido nos termos da justiça social (17).

Mais uma contribuição interessante para a BI pode advir de outra importante voz do sul, a filosofia africana. Aqui dialogaremos com a noçáo banta de ubuntu, conceito importante para o pensamento ético e político africano.

Diversos autores tem defendido a possibilidade de pensar a justiça a partir desta noção $(18,19,20)$. A palavra ubuntu é derivada da palavra ntu em uma das muitas línguas bantas. Ntu seria o princípio dinâmico de toda a existência no mundo e ubuntu representaria o caráter relacional, intrinsecamente coletivo, da humanidade (20). Pensar a humanidade desde a perspectiva ubuntu, significa a inexistência de um indivíduo isolado, pois ele está sempre ontologicamente vinculado a todas as pessoas da coletividade.

Segundo o filósofo moçambicano Severino Ngoenha, a mais importante reivindicação feita pelo pensamento africano é o reconhecimento da dignidade humana dos africanos (19). Podemos pensar que essa reinvindicaçáo possa ser estendida a todos os povos do sul que têm suas presenças no mundo subhumanizadas pela colonialidade da vida (3). E, nesse cenário, a discussão sobre ubuntu assume um lugar central para a discussão sobre justiça social, pois pensa a necessidade de considerar a alteridade, os outros como humanos e não apenas por uma questão de reconhecimento político, mas por uma necessidade éticoontológica de pensar a humanidade como um todo.

Se há alguma pessoa que seja desconsiderada como humana, subhumanizada, a humanidade sofre como um todo. Isso significaria inverter a lógica colonial da falácia desenvolvimentista, que implicava em considerar algumas pessoas menos humanas para poder educá-las, tutelá-las e conduzi-las a um estágio de desenvolvimento próximo ao do ocidente, para com isso o mundo inteiro se beneficiar do progresso moderno-ocidental (3). É preciso considerar que todos são igualmente humanos para que a humanidade náo continue indo 
em direção à bancarrota, mesmo que alguns grupos econômica e socialmente privilegiados (do norte) sintam isso de maneira atenuada.

É assim que a perspectiva ubuntu apareceria como um marco de justiça restaurativa e distributiva, com um direcionamento para a justiça social. A preocupação do pensamento africano com as diversas formas de exploraçáo e com a pobreza absoluta fez com que ele ocupasse um espaço de maior visibilidade nas discussóes acadêmicas internacionais e, assim, possa oferecer contribuiçóes substantivas a um diálogo com o ocidente.

O ubuntu pode ser visto como um princípio de justiça restaurativa exatamente na medida em que visualiza o fato de que parte do mundo, tal como o experimentamos cotidianamente, é atravessada pela injustiça, pela exploração, pelo menosprezo da maior parte da populaçáo mundial pelo esquema pernicioso de expropriação do ocidente. O pensamento, desde a perspectiva ubuntu, percebe que os esquemas de exploração que empobrecem e violam a maior parte da população mundial causa um dano coletivo e total à humanidade e é preciso reparar a isso, restaurando a dignidade de todas as pessoas, da coletividade, buscando a harmonia da força vital que habita em cada uma das pessoas do planeta (20).

É por isso que a ética ubuntu é fundamentalmente solidária: é necessário comover-se com uma situação precária e que alguém passe a se posicionar sobre isso (20). E longe de ser um gesto meramente altruísta, é uma postura de amor à totalidade da humanidade que habita em cada um dos existentes humanos; é um reconhecimento de que se há algo que precariza a vida de uma só pessoa, pode precarizar também a totalidade da humanidade, e normalmente o faz. É a busca da harmonia humana, radicalmente coletiva, que torna o ubuntu um princípio de justiça social.

Se não formos iguais na distribuição dos recursos, na justiça, inevitavelmente o seremos na disposição à precariedade, embora alguns saibam se aproveitar melhor disto do que outros: o que mantém o mundo invariavelmente numa situação global de injustiça. Por isso, ubuntu aparece como um princípio que sustenta que ajamos humanamente e com respeito aos outros humanos como modo de demandar a mesma conduta para nós - e para todas as pessoas (18).

\section{Consideraçóes finais: aportes para a Bioética de Intervençáo}

$\mathrm{Na}$ tarefa de contribuir para o fortalecimento das bases conceituais da $\mathrm{BI}$, que reivindica um enraizamento e um comprometimento com os lugares vulnerados do sul, apresentamos algumas perspectivas sobre justiça que possam se aliar às já apresentadas pela BI, com o objetivo de oferecer vozes para o diálogo que esta própria perspectiva bioética nos apresenta como estratégia importante de sua atuação (3).

A BI, em sua crítica ao principialismo bioético, assinala a primazia 
da autonomia, primeiramente individual, sobre o princípio de justiça, eminentemente coletivo $(1,2)$. Com isso ela afirma uma postura coletivista sobre os conflitos morais que envolvam a vida e a saúde. Entretanto, sabemos que não há garantias de um uso não individualista do princípio de justiça, quando o contexto de aplicação da mesma é a sociedade liberal $(13,19)$.

Nesse sentido, a apresentação das duas perspectivas sobre justiça desde as miradas do sul podem ser profícuas para o contexto de justiça que a BI busca - a justiça social: elas se assentam sobre um coletivismo radical ético, político e ontológico. A preocupaçáo com a alteridade e o todo da humanidade é fundamental para essas perspectivas e isso se coaduna de modo interessante aos propósitos da BI.

A percepção da injustiça, para seu enfrentamento, que é a marca da afirmação dialética da justiça social pouco tematizada, mas constantemente afirmada pela BI, encontra amparo nas duas percepçóes apresentadas. Tanto o contexto intercultural, no qual se forjou a noção andina de justiça que nos chega, como o caráter restaurativo da noçáo de justiça afirmada pela perspectiva ubuntu. Essas perspectivas partem do concreto fato da vulneração das comunidades nos sistemas de exploraçáo. Não são a utopia de um mundo que parta de um marco zero no qual as desigualdades inexistam, mas se apresentam como uma proposta de ação para um mundo desigual que busque a igualdade através da equidade, o que é também afirmado pela BI, de modo que um diálogo interessante possa se dar em torno desse aspecto.

Em que pese as possíveis contribuiçôes das teorias advindas do mundo andino tradicional e do mundo banto, algumas questóes ficam em aberto para a discussão e a possibilidade do diálogo. Frisamos aqui duas delas, que giram em torno da reciprocidade e do caráter comunitário da justiça.

Em virtude da assimetria de poder entre os grupos explorados e os grupos detentores de poderes políticos e econômicos, é bastante difícil pensar na proposta da reciprocidade, pois ela implicaria que os grupos privilegiados política e economicamente estivessem dispostos a assumir sua participação na atividade recíproca. O abandono da zona de conforto para atuar em favor do coletivo pode parecer uma proposta inócua. Suspeitamos que aqui devesse haver uma atuação do estado na mediação dessa dificuldade. A redistribuição de recursos e serviços náo pode ser responsabilidade dos grupos privilegiados. E aqui a proposta é por um estado que seja capaz de articular essa redistribuiçáo e se responsabilizar pelas condiçóes da justiça. Uma importante tarefa para a intervenção do estado, que deve ser todo repensado em função de que, nas condiçóes atuais, ele é composto de modo substantivo pelas elites privilegiadas. Aqui, a educação política e moral é fundamental para que as comunidades possam estar cientes de seu papel na constituiçáo dos estados, assim como o fortalecimento dos vínculos do estado com os movimentos sociais desempenha um papel absolutamente relevante. Entretanto, os caminhos dessa discussão seguem abertos. 
E é essa relação com o estado que nos leva à segunda questáo que anunciamos. Tanto nas proposiçóes andinas quanto no contexto da proposta ubuntuísta, as comunidades ocupam um lugar privilegiado na instância das articulações em torno da justiça social. Entretanto, na atual configuração de nossas sociedades, sobretudo a partir das perspectivas contratualistas liberais, ora o estado, ora o mercado são responsáveis pela condução do processo da justiça social. A questáo imperante é: como lidar com as relaçóes de interesses nem sempre coincidentes entre as comunidades e o estado? Esse é um problema bastante complexo e que demanda uma série de outras reflexóes que possam se articular com a necessidade da resposta. Entretanto, as experiências interculturais que ocorrem nesse exato momento em países como a Bolívia, o Equador e a África do Sul podem servir de exemplos para pensar essa questão, embora esse problema ainda náo tenha sido plenamente resolvido nesses países.

De toda maneira, a possibilidade de pensar em ferramentas teóricas desde o sul, que contribuam com as bases conceituais da BI, parecem fortalecidas em sua coerência política ao ouvir as vozes andinas e africanas. O trabalho é longo e difícil, mas devemos nos impor a tarefa de iniciá-lo, se apostamos na pertinência e importância das propostas da bioética de intervençáo.

*Trabalho desenvolvido no programa de pós-graduação em Bioética da Universidade de Brasilia.

\section{Referências}

1. Garrafa V, Porto D. Intervention Bioethics: a proposal for peripheral countries in a context of power and injustice. Bioethics. 2003;17(5-6):399-416.

2. Porto D, Garrafa V. Bioética de intervenção: consideraçóes sobre a economia de mercado. Bioética. 2005;13(1):111-123.

3. Nascimento WF, Garrafa V. Por uma vida náo colonizada - diálogo entre Bioética de Intervenção e Colonialidade. Saúde e Sociedade. 2011;20:287-299. 4. Gonçalves ER, Ramos FR, Garrafa V. O olhar da bioética de intervenção no trabalho do cirurgiáo-dentista do Programa Saúde da Família (PSF). Revista Bioética. 2010;18(1):225-239.

5. Sem A. Desenvolvimento como liberdade. São Paulo: Companhia das Letras; 2000.

6. Silva LES, Drummond A, Garrafa V. Bioética de intervenção: uma prática politizada na responsabilidade social. Universitas: Ciências da Saúde. 2011;9(2):111-119.

7. Siqueira JE. O princípio de justiça. In: Costa SIF, Oselka G, Garrafa V, organizadores. Iniciação à bioética. Brasília: Conselho Federal de Medicina; 1988. p. 71-80.

8. Selli L, Garrafa V. Solidariedade crítica e voluntariado orgânico: outra possibilidade de intervenção societária. História, Ciências, Saúde - Manguinhos. 
2006;13(2):239-51.

9. Garrafa V. Da bioética de princípios a uma bioética interventiva. Bioética. $2005 ; 13(1): 125-134$.

10. Garrafa V. Inclusão social no contexto da bioética. Revista Brasileira de Bioética. 2005; 1(2):122-132.

11. Garrafa V. Ampliação e politização do conceito internacional de bioética. Revista Bioética. 2012;20(1):9-20.

12. Santos IL, Garrafa V. Análise da Declaração Universal sobre Bioética e Direitos Humanos da Unesco à luz da ética de Paulo Freire. Revista Redbioética/ UNESCO. 2011;1(3):130-135.

13. Segato RL. El color de la cárcel en América Latina: apuntes sobre la colonialidad de la justicia en un continente en desconstrucción. Nueva sociedad. 2007;208:142-161.

14. Alarcón S. La justicia comunitaria como sustento de la ética aymara. Revista Integra Educativa. 2009;2(3):253-278.

15. Lang M. Presentación. In: Santos BS, Jiménez AG, organizadores. Justicia indígena, plurinacionalidad e interculturalidad en Ecuador. Quito: Fundación Rosa Luxemburg/Abya Yala; 2012. p. 9-12.

16. Santos BS. Cuando los excluidos tienen Derecho: Justicia indígena, plurinacionalidad e interculturalidad. In: Santos BS, Jiménez AG, organizadores. Justicia indígena, plurinacionalidad e interculturalidad en Ecuador. Quito: Fundación Rosa Luxemburg/Abya Yala, 2012, p. 13-50.

17. Estermann J. Filosofía andina. Sabiduría indígena para un mundo nuevo. La Paz: ISEAT; 2006.

18. Ramose MB [internet]. Una perspectiva africana sobre la justicia y la raza. Poylog. Foro para filosofía intercultural - [acesso em 24/Abr/2013]. Disponível em: http://them.polylog.org/3/frm-es.htm

19. Ngoenha SE. Ubuntu: New model of global justice? Indilinga: African Journal of Indigenous Knowledge Systems. 2006;5(2):125-134.

20. Kashindi JBK [internet]. "Ubuntu” como modelo de justicia restaurativa. Un aporte africano al debate sobre la igualdad y la dignidad humana. Actas del XIII Congreso Internacional del Asociación Latinoamericana de Estudios de Asia y África. La ética del sur - [acesso em 24/Abr/2013]. Bogota: ALADAA.2011. http://ceaa.colmex.mx/aladaa/memoria_xiii_congreso_internacional/images/kakozi.pdf.

Recebido: 27/05/2012 Aprovado: 30/07/2012 